\title{
Correction to: Preclinical assessment of transiently TCR redirected T cells for solid tumour immunotherapy
}

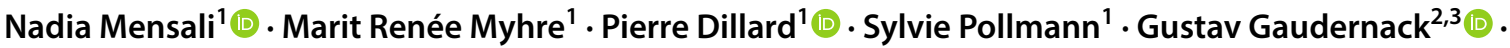

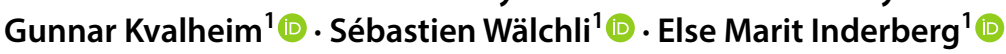

Published online: 27 November 2019

(c) The Author(s) 2019

\section{Correction to: \\ Cancer Immunology, Immunotherapy \\ (2019) 68:1235-1243 \\ https://doi.org/10.1007/s00262-019-02356-2}

The original version of this article unfortunately included a mistake in Fig. $2 b$ where the images of mice in the tumour control group (right), day 30 (bottom) should be removed as the wrong images (duplicate of day 17) were inserted by mistake. At this time point the tumour control mice were no longer alive and the images were replaced by black areas.

The revised Fig. 2 is placed on the following page.

The original article can be found online at https://doi.org/10.1007/ s00262-019-02356-2.

Sébastien Wälchli

sebastw@rr-research.no

$\triangle$ Else Marit Inderberg

elsmar@rr-research.no

1 Department of Cellular Therapy, Department of Oncology, Oslo University Hospital, The Norwegian Radium Hospital, 0379 Oslo, Norway

2 Department of Cancer Immunology, Institute for Cancer Research, Oslo University Hospital, The Norwegian Radium Hospital, 0379 Oslo, Norway

3 Faculty of Medicine, University of Oslo, 0316 Oslo, Norway 
A

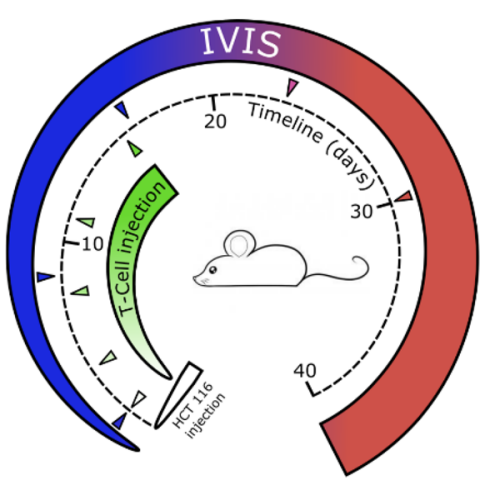

C

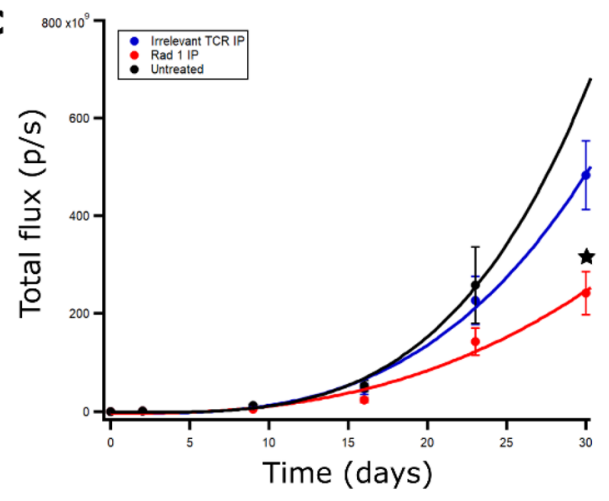

E

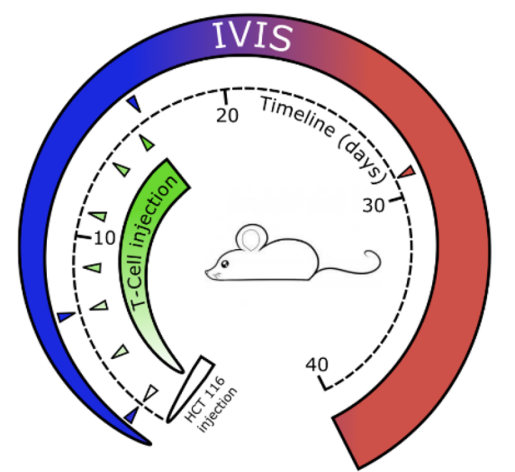

G

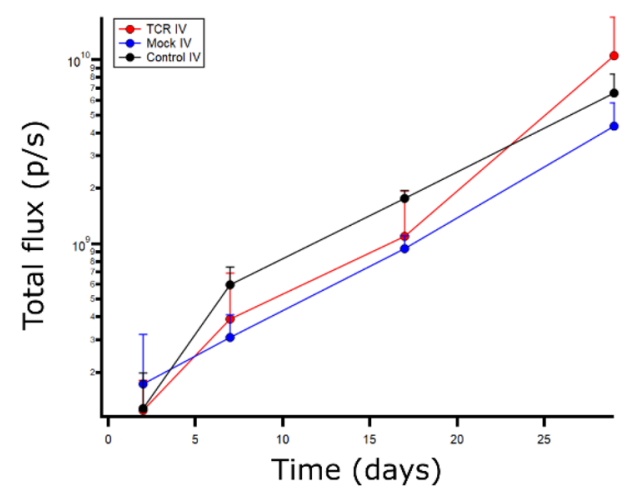

B Time Intraperitoneal Tumor

(days) Radium-1 Tc Irrelevant Tc control

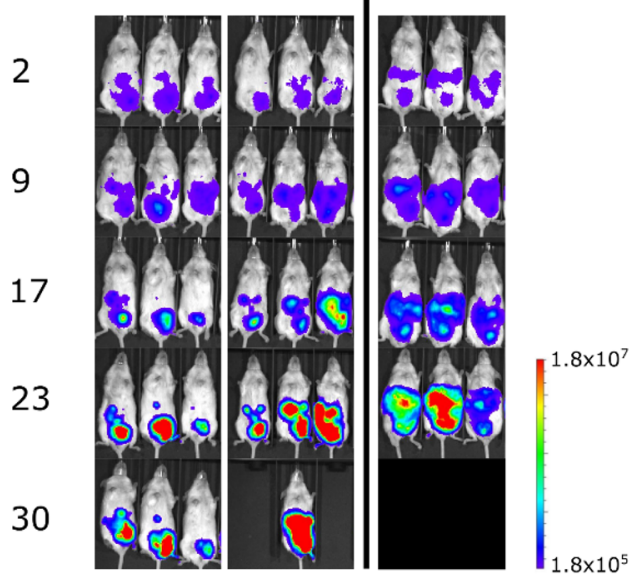

D

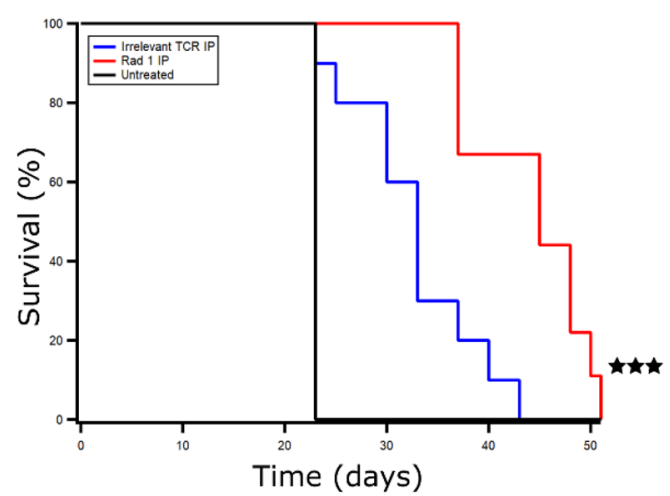

$\mathbf{F}$

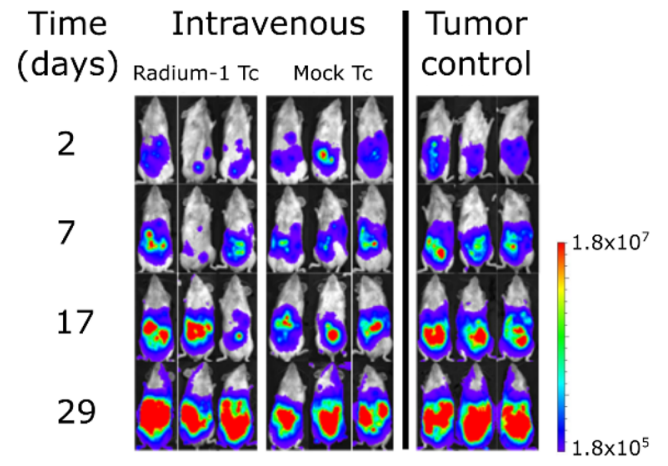

H

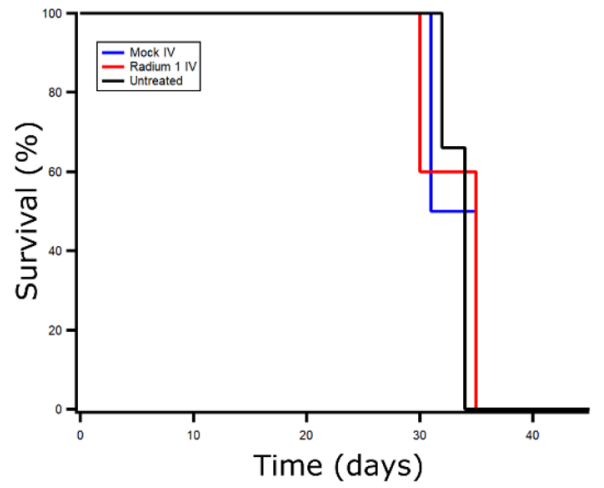


4Fig. 2 In vivo efficacy of transiently transfected T cells depends on route of administration. (a) NSG mice were injected i.p. with $10^{6}$ HCT 116 ff-Luc 2 days before injection of T cells. T cell treated groups were treated on days $2,4,8,11$, and 16 with Radium-1 TCR or irrelevant TCR expressing T cells i.p. $(n=10)$. The Radium-1 TCR group was treated with $10^{7}$ Radium-1 TCR electroporated T cells at each injection, the irrelevant TCR group $(n=10)$ was treated with $10^{7}$ DMF5 TCR electroporated T cells at each injection i.p. Tumour control received no treatment $(n=4)$. Three mice from each group are shown. (b) Tumour load was evaluated by bioluminescence imaging on days $2,9,17,23$, and 30. Black areas indicate loss of mice. (c) Average tumour load (total flux photons/s) in the different groups are shown ( $p=0.031$ and 0.0089). (d) Survival time of the different treatment groups after tumour injection $(p=0.0072)$. The results shown are representative of three independent experiments. (e) Radium-1 Tc treated group $(n=5)$ and mock electroporated Tc treated group $(n=4)$ were treated with $10^{7} \mathrm{~T}$ cells i.v. at indicated time points. The tumour control group $(n=3)$ was not given any treatment. (f) Tumour load was evaluated by bioluminescence imaging on days 2, 7, 17, and 29 . (g) Average tumour load (total flux photons/s) in animals given $\mathrm{T}$ cells i.v. and control group, (h) Kaplan-Meier animals given T cells i.v. and control group
Open Access This article is distributed under the terms of the Creative Commons Attribution 4.0 International License (http://creativecommons.org/licenses/by/4.0/), which permits unrestricted use, distribution, and reproduction in any medium, provided you give appropriate credit to the original author(s) and the source, provide a link to the Creative Commons license, and indicate if changes were made.

Publisher's Note Springer Nature remains neutral with regard to jurisdictional claims in published maps and institutional affiliations. 